\title{
Impact of Neuroticism on Alexithymia and Marital Satisfaction Among Married Men and Women
}

\author{
Khushboo Shah ${ }^{1}$, Reshma Murali ${ }^{2}$ \\ ${ }^{1}$ Post Graduate Student, Smt. Maniben M.P. Shah Women's College of Arts and Commerce, Mumbai. \\ ${ }^{2}$ Assistant Professor, Department of Psychology, Smt. Maniben M.P. Shah Women's College of Arts and \\ Commerce, Mumbai. \\ Corresponding author: Khushboo Shah \\ Email-khushs1994@gmail.com
}

\begin{abstract}
Background and Objectives: The present study focused on three variables namely Neuroticism, Alexithymia and Marital Satisfaction. Neuroticism is a general tendency to experience negative affect, and people high in Neuroticism are prone to have irrational ideas, be less able to control their impulses, and to cope more poorly than others with stress. Alexithymia, on the other hand, is seen as a cluster of deficits in the experiencing, expression and regulation of emotions. Marital Satisfaction is often defined as the attitude an individual has toward his or her marital relationship. The aim of the present study was to study the impact of Neuroticism on Alexithymia and Marital Satisfaction among Married Men and Women. In addition, the study also explored the relationship between Alexithymia and Marital Satisfaction.

Methods: The study was conducted on fifty married heterosexual couples (50 Males, 50 Females) to examine the impact of Neuroticism on Alexithymia and Marital Satisfaction. A convenient, snowball sampling method was used to get responses from 100 participants. The three variables were studied using three tests, one for each variable. These consisted of Eysenck Personality Questionnaire-Revised, 20 item Toronto Alexithymia Scale (TAS-20) and Enrich Marital Satisfaction Scale.

Results: All the three statistical analyses were found to be significant and in line with the results. The results supported the hypotheses and thus implicated that Neuroticism does have an impact on Alexithymia and Marital Satisfaction among married couples.

Conclusion: Further studies in larger samples are need to establish and corroborate the findings of the study.
\end{abstract}

Keywords: Neuroticism, Alexithymia, Marital Satisfaction.

(Paper received $-9^{\text {th }}$ October 2017, Peer review completed $-20^{\text {th }}$ December 2017)

(Accepted $-24^{\text {th }}$ January 2018)

\section{INTRODUCTION}

Three perspectives that have largely influenced the study of marriage have been discussed here in this paper viz.

Social Exchange Theory: This theory draws from Thibaut and Kelley's theory of interdependence [1] and it states that "relationships grow, develop, deteriorate, and dissolve as a consequence of an unfolding socialexchange process, which may be conceived as a bartering of rewards and costs both between the partners and between members of the partnership and others" [2]. According to this perspective, "marriages end when the attractions of the relationship are few, the barriers to leaving the relationship are weak, and the alternatives to the relationship are enticing". Using these ideas, Lewis and Spanier [3] formed an exchange typology of marital relationships according to which marriages can be satisfied and stable, satisfied but unstable, unsatisfied but stable, or unsatisfied and unstable. 
Behavioural Theory: The basic elements of this theory of marriage are rewards and costs. However, it focuses on interpersonal exchange of behaviours that are specific. Research has concentrated on behaviours that are exchanged during problem-solving discussions. It has been guided by the assumption that positive behaviours enhance evaluations of marriage whereas negative behaviours does harm to it [4-5]. This model suggests that cognitive responses have an impact on marriage by influencing subsequent interaction behaviours. Over time, the accumulation of experiences during and after interaction is thought to gradually influence spouses' judgments of marital quality [6-7].

Attachment Theory: This theory of marriage is influenced by Bowlby's [8] work on relationships between infants and their primary caregivers. Bowlby suggested that initial close relationships provides a framework to the child about how close relationships are like, which in turn determines an individual's close relationships throughout life. Three major attachment styles emphasized by this theory are secure attachment (usually seen between mothers and infants, considered to be the ideal style), anxious-ambivalent attachment (inconsistently responsive parents whose children simultaneously crave and resent the caregiver) and anxious-avoidant attachment (irresponsive parents whose children avoid the caregiver without any separation distress).

\section{Marital Satisfaction and Alexithymia}

Given the importance of emotion in relationships [9] and emotional compatibility between couple partners [10], it seems plausible that alexithymia would be a contributing factor to the quality of couples' relationships. Clinical reports have suggested that, when entering into a close relationship with someone who is highly alexithymic, those who are unfamiliar with the construct's characteristics can initially be misled by observations of a highly functioning and successful individual who seems super-adjusted [11]. When partnered with such individuals, relationships often start well; however, interpersonal difficulties may arise when the couple's interactions cannot move past superficial functioning and communication to a deeper and more emotionally meaningful connection, which may be particularly difficult for a partner who is more emotionally aware and expressive [12].

\section{Marital Satisfaction and Neuroticism}

In a review of literature on personality and marriage, it was concluded that Neuroticism was the trait most strongly associated with negative marital outcomes [13]. It has been demonstrated that high Neuroticism prior to marriage was strongly predictive of marital dissatisfaction and divorce over 45 years [14]. Two theoretical perspectives can explain this link. First, interpersonal models [13] suggest that those higher in Neuroticism should be less satisfied with their relationships because they tend to create negative life events through negative behaviour and emotional contagion. Second, intrapersonal models [14] suggest that those higher in Neuroticism are less satisfied with their relationships because they are less satisfied with their lives generally, possibly because they perceive life events more negatively.

\section{Marital Satisfaction, Neuroticism and Alexithymia: Interrelationships}

Since all the constructs discussed above has as their core the interplay of emotions, it becomes crucial to analyse the relationships they share. This is to say that, marital satisfaction, alexithymia and neuroticism, though in direct or indirect relationship, strong or weak magnitude, positive or negative light; share the complex interrelations woven by the most basic and most important construct that makes us undoubtedly human: emotions.

The aim of the present study was to study the impact of Neuroticism on Alexithymia and Marital Satisfaction among Married Men and Women. The study was done in order to understand the role played by Neuroticism in determining Alexithymia and Marital Satisfaction among Married Men and Women and to study if there existed any relationship between Alexithymia and Marital Satisfaction among Married Men and Women.

\section{Hypotheses:}

H1: There is a difference in the level of Alexithymia between individuals with high Neuroticism and those with low Neuroticism. 
H2: There is a difference in the level of Marital Satisfaction between individuals with high Neuroticism and those with low Neuroticism.

\section{METHODOLOGY}

Participants: Fifty heterosexual couples married for 5 years to 25 years were used as participants. The participants were recruited using snowball and convenient sampling.

Controls: A sample size of 100 participants required few controls to ensure the significance of data that was obtained. The sample was restricted to Mumbai city and included only those couples who were married for 5 to 25 years. Moreover, the sample excluded those couples who had undergone divorce or were remarried. Lastly, the sample was matched on their socio-economic background to maintain the comparison of data.

Operation Definition of Variables:

1. Neuroticism: It is defined as a general tendency to experience negative affect. Individuals with scores below 4 on EPQ-R (Neuroticism) would be considered as being low on the factor of Neuroticism, whereas those with a score above 7 on EPQ-R (Neuroticism) would be considered as having higher levels of Neuroticism.

2. Alexithymia: It refers to several difficulties that people face with respect to aspects of emotions i.e. identifying emotions, describing it as well as expressing it. It is measured using a 20 item Toronto Alexithymia Scale. Individuals with a score of 50 and below would be considered as Non-Alexithymics whereas those with a score of 61 and above would be considered as Alexithymics.

3. Marital Satisfaction: In this study, it refers to the mental state that reflects the perceived benefits and costs of a particular person, married people are either happy, and enjoying their marriages or they are not, here we refer to their level of satisfaction within their marriage as they view it. It is measured by means of a 15 item ENRICH Marital Satisfaction Scale which has been found to have good reliability and validity.

Tools:

Neuroticism, Alexithymia and Marital Satisfaction are broad constructs, each requiring special attention for a detailed review. Hence, three separate scales, one for each variable, will be used in this study. These three scales are as follows:

\section{Eysenck's Personality Questionnaire Revised (EPQ-R)}

To assess the couple's Neuroticism levels, Eysenck Personality Questionnaire - Revised (EPQ-R) will be used. The 90-item Eysenck Personality Questionnaire (EPQ) is a self-report measure that operationalizes Eysenck's model of personality. The EPQ measures three traits of personality along with an additional lie scale. These are: Psychoticism (P), Extraversion (E), Neuroticism (N) and Lie Scale (L). Reliability ranges are 0.80 to 0.90 and validity of test is satisfactory. EPQ-R contains 90 items and covers all the four categories above mentioned. Scoring of EPQ-R can be done manually or with the help of stencils. A score of 1 is given for each correct response (correct responses according to scoring key). After calculation of raw scores of $\mathrm{P} \mathrm{E}$ $\mathrm{N} \mathrm{L}$, there is a conversion table to convert raw scores into Sten Scores. The score of 5-6 denotes average strength of the factor (P, E, N, L); scores above 6 i.e. from 7- 10 express gradually the greater strength of the factor and scores below 5, i.e. from 1-4 indicates gradual decrease of strength [16].

\section{Twenty Item Toronto Alexithymia Scale (TAS-20)}

This scale contains 20 items, and the most widely used to gauge Alexithymia. It is a self-report test that utilizes a 5 point Likert scale [17]. Scores can range from 20 to 100 with the higher numbers representing a higher tendency for the Alexithymia construct [18]. The TAS-20 yields three factors in the most widely accepted format. It has an alpha coefficient greater or equal to 0.70 which is a recommended standard for establishing internal reliability [19]. With regard to validity, the TAS-20 scale does appear to have discriminate validity. The total alexithymia score is the sum of responses to all 20 items, while the score for each subscale factor is the sum of the responses to that subscale. The TAS-20 uses cutoff scoring: equal to or less than $51=$ non-alexithymia, equal to or greater than $61=$ alexithymia. Scores of 52 to $60=$ possible alexithymia. It is divided into 3 subscales: Difficulty Describing Feelings (DDF) 5 items (questions 2, 4, 7 , 
12, 17); Difficulty Identifying Feeling (DIF) subscale 7 items ( questions 1, 3, 6, 11, 9, 13, 14); ExternallyOriented Thinking (EOT) subscale is used to measure the tendency of individuals to focus their attention externally 8 items (questions $5,8,10,15,16,18,19,20$ )

\section{Enrich Marital Satisfaction Scale}

The EMS Scale is a 15-item scale comprising the Idealistic Distortion (5 items) and Marital Satisfaction scales (10 items). Each of the 10 Marital Satisfaction items represents one of the areas of the marital relationship assessed by the full-length ENRICH Inventory (e.g. communication or sexual relationship). Thus, the EMS Scale provides a 1-item sampling of the 10 dimensions of marital satisfaction found to be most important whose conclusions about the important domains of marital satisfaction provide an indication of the content validity of the EMS Scale. The 5 items from the Idealistic Distortion scale constitute a marital conventionalization scale. It is a modified version of the Edmonds Marital Conventionalization Scale [20]. It correlates highly with other scales that measure marital conventionalization and has an alpha coefficient of 0.92 and a 4 -week test-retest reliability of 0.92 . The score on this scale is used to correct the Marital Satisfaction scale score on the basis of the degree to which the respondent portrays the marriage in an impossibly positive way. The EMS Scale provides a score for each partner. This score is derived by first scoring the Marital Satisfaction and Idealistic Distortion scales, then correcting the Marital Satisfaction score downward on the basis of the person's idealistic Distortion score [21].

\section{Research Design:}

The variables of this study i.e. Neuroticism, Alexithymia and Marital Satisfaction were studied in different combinations. Hence, this research consisted of a quasi-experimental and correlational design. A causal relationship was studied to see the impact of Neuroticism on Alexithymia and Marital Satisfaction among Married Couples. Moreover, it was also seen whether any relationship existed between Alexithymia and Marital Satisfaction.

\section{Procedure:}

Hundred participants were recruited for the study using snowball and convenient sampling. The participants consisted of fifty heterosexual married couples (50 Males, 50 Females). After the participants were recruited, they were informed about the study to be conducted and they were given a set of questionnaires to fill. Firstly, the participants were asked for their consent to participate in the study by giving them a consent form. After that, they were instructed to provide their demographic details and fill the questionnaires honestly since there was no right or wrong answers. They were assured about the confidentiality of their responses. Depending on the participant's convenience, the questionnaires were either filled on the spot or they were given to them to take it at home and return it when they were done filling it. Queries were responded to via email and the data was collected. Those participants who had expressed a wish to know their results were contacted once the data analysis was over and were given their results.

\section{STATISTICAL ANALYSIS}

1. Two t-tests were conducted in this study. It was done in order to determine if the mean difference between the two groups was significant or not. After screening the participants on Neuroticism, one t-test was conducted to see whether significant difference existed between scores of Neuroticism and Alexithymia, and the other t-test took into consideration Neuroticism and Marital Satisfaction Scores.

2. Pearson's Product Moment Correlation was conducted by taking into consideration Alexithymia and Marital Satisfaction and to see the pattern of relationship they shared with each other.

\section{RESULTS}


Table 1 indicates the calculated means and standard deviations for Alexithymia and Marital Satisfaction for individuals with low and high scores on Neuroticism.

Table 1 Calculated Means and Standard Deviations for the respective variables

\begin{tabular}{|l|l|l|l|l|}
\hline & Neuroticism & N & M & \multicolumn{1}{|c|}{ SD } \\
\hline \multirow{3}{*}{ Alexithymia } & Low & 45 & 44.02 & 9.79 \\
\cline { 2 - 5 } & High & 55 & 56.67 & 10.49 \\
\hline \multirow{2}{*}{$\begin{array}{l}\text { Marital } \\
\text { Satisfaction }\end{array}$} & Low & 45 & 57.56 & 6.69 \\
\cline { 2 - 5 } & High & 55 & 49.03 & 13.39 \\
\hline
\end{tabular}

With respect to the above table, it can be seen that the mean Alexithymia scores for individuals who scored low on Neuroticism was 44.02 and for those who scored high on Neuroticism was 56.67. Standard Deviations for the same were found to be 9.79 and 10.49 respectively. In addition, the mean Marital Satisfaction scores for those with low Neuroticism was 57.56 and those with high Neuroticism was 49.03 and the Standard deviations for the same were 6.69 and 13.39 respectively.

Table 2 Mean differences in Alexithymia and Marital Satisfaction between individuals with Low and High Neuroticism

\begin{tabular}{|l|l|l|l|}
\hline & $\mathrm{t}$ & $\mathrm{df}$ & $\begin{array}{l}\text { Sig. } \\
\text { tailed })\end{array}$ \\
\hline Alexithymia & -6.182 & 98 & .0001 \\
\hline $\begin{array}{l}\text { Marital } \\
\text { Satisfaction }\end{array}$ & 3.895 & 98 & .0001 \\
\hline
\end{tabular}

In order to determine if there existed a significant difference between the means of the two groups each on Alexithymia and Marital Satisfaction, two independent samples t-test were conducted. As can be seen from table 2, the mean difference between the two groups on Alexithymia i.e. Alexithymia scores of individuals with low Neuroticism and high Neuroticism was found to be -6.18 which was significant at 0.01 level $[t(98)=-6.18, p<0.01)]$. Hence, a significant relationship existed between the two groups. Similarly, the mean difference between the two groups on Marital Satisfaction i.e. those with high and low Neuroticism was found to be 3.90 and it was also significant at 0.01 level of significance $[t(98)=3.90, p<0.01)]$. Thus, there existed a significant difference between the means of the two groups.

Table 3 Pearson's Product Moment Correlation between Alexithymia and Marital Satisfaction Correlations

\begin{tabular}{|l|l|l|l|}
\hline & & Alexithymia & MS \\
\hline Alexithymia & \multirow{2}{*}{$\begin{array}{l}\text { Pearson } \\
\text { Correlation }\end{array}$} & 1 & $-.394^{* *}$ \\
\cline { 3 - 4 } & Marital & & \\
Satisfaction & $\begin{array}{l}\text { Pearson } \\
\text { Correlation }\end{array}$ & $-.394^{* *}$ & 1 \\
\cline { 3 - 4 } & $*$. Correlation is significant at the 0.01 level (2-tailed). & \\
\hline
\end{tabular}

The present study was also conducted to determine if there existed any relationship between Alexithymia and Marital Satisfaction. In order to determine this relationship, Pearson's Product Moment Correlation was conducted between Alexithymia and Marital Satisfaction. As can be seen in 
table 3, the Pearson's $r$ value obtained was -0.39 and it was found to be significant at 0.01 level of significance. $(r=-0.39, p<0.01)$. Thus, there existed a very strong negative relationship between the two variables.

\section{DISCUSSION}

The existing results are in line with the findings of other research conducted on the mentioned variables i.e. Neuroticism and Alexithymia. Some findings relevant to the present study are as follows. Rubino and others [22] reported a significantly higher level of Alexithymia in neurotic and delusional patients than in psychosomatic patients, and concluded that Alexithymia is not a non-neurotic personality dimension. Espina [23] investigated Alexithymia among parents of daughters with eating disorders (EDs) and related Alexithymia to personality and psychopathology characteristics. Parents of 73 women with ED and parents of 72 normal women were evaluated with the Toronto Alexithymia Scale (TAS-20), the Eysenck Personality Questionnaire, the Beck Depression Inventory and the Self-Rating Anxiety Scale. It was found that the parents of daughters with ED showed higher scores in the TAS-20 and its factors than the controls. TAS-20 scores of parents were associated with Neuroticism, Anxiety and Depression.

Hypothesis two stated that "There is a difference in the level of Marital Satisfaction between individuals with high Neuroticism and those with low Neuroticism". A two-tailed t-test was conducted between the mean Marital Satisfaction scores of individuals who had higher levels of Neuroticism and those with low Neuroticism. Results revealed that the mean differences between these two groups were highly significant. In other words, the results supported the hypothesis indicating that Neuroticism also tends to have an impact on one's level of satisfaction within a marriage.

Cramer [24] in a large scale, nationally representative 1984/5 Health and Lifestyle Survey of British adults, found that Neuroticism and Extraversion (as measured by the Eysenck Personality Inventory) were higher in the 200 women and 99 men who had separated or divorced than in the 1836 women and 1734 men who remained married. When such potentially confounding factors as the Lie scale score, age and social class were partialled out, Neuroticism and Extraversion remained greater in the women but not the men who had separated or divorced. Although not large, the findings provide further support that these personality factors may be involved in marital dissolution.

Karney and Bradbury [13] reported in their meta-analytic review that Neuroticism exerted consistent longterm effects on the Marital Satisfaction of wives and husbands. These results refer to so-called actor effects, that is, how the Neuroticism of the individual person affects his or her individual satisfaction with the relationship. In relationship research, however, the complementary perspective is of interest, too: How does a person's personality affect the relationship satisfaction of his or her partner? Malouff and others [25] investigated these so-called partner effects in a meta-analysis and found that Neuroticism again showed an average correlation with the partner's Relationship Satisfaction.

Caughlin, Huston, and Houts [26] investigated dysfunctional interpersonal behaviours such as negatively valenced communication (i.e. criticism, complaints, expression of anger) in a 13-year longitudinal study with newlywed couples, they found that initial neuroticism consistently predicted Marital Negativity, which in turn was associated with partner's Marital Dissatisfaction. McNulty [27] argued that Neuroticism leads to negative relationship outcomes because neurotic people create negative interpersonal experiences through reciprocity effects of their own negative behaviours. In particular, he assumed that a person's negative behaviours would lead to negative partner behaviours and that negative expectancies would lead to biased perceptions of interpersonal behaviours, which in turn would result in lower satisfaction in neurotic individuals. McNulty found partial support for his assumptions and drew conclusions about the importance of Neuroticism for biased cognitive processes.

Hanzal and Segrin [28] highlighted the impact that communication processes have at a dyadic level in marital relationships. They examined the role of Negative Affectivity and Conflict Styles on newlywed couples' marital satisfaction. The vulnerability-stress-adaptation (VSA) model of marital development was used to explain relationships between enduring vulnerabilities, adaptive processes, and marital quality. Dyadic analyses and tests of mediation were performed on data from 194 couples in the first 5 years of their marriage. Results indicated that wives' negative affectivity was significantly associated with their own lower 
Marital Satisfaction and husbands' lower Marital Satisfaction. However, husbands' negative affectivity was only associated with their own lower Marital Satisfaction. For all spouses, negative affectivity was associated with a tendency to engage in more dysfunctional conflict styles. Tests of mediation indicate that positive problem solving, and to a lesser extent, conflict engagement, and withdrawal were able to partially explain the relationship between negative affectivity and marital quality.

In order to see whether any relationship existed between Alexithymia and Marital Satisfaction, the following research question was asked: "Is there any relationship between Alexithymia and Marital Satisfaction?" For this purpose, a Pearson's Product Moment Correlation was conducted between the two variables and the $r$ value was found to be statistically significant indicating that the two variables shared a very strong negative relationship with each other. In other words, Alexithymia and Marital Satisfaction were inversely related to each other i.e. increase in one variable led to decrease in the other variable and vice versa. Some of the possible reasons for the above found relationship could be found in the theories and findings of earlier researches which are as follows.

$\mathrm{Li}$ and Fung [29] proposed the dynamic goal theory of Marital Satisfaction to integrate previous findings about Marital Satisfaction from a life span developmental perspective. The theory argues that people have multiple goals to achieve in their marriage. These marital goals can be classified into three categories: personal growth goals, companionship goals, and instrumental goals. The priority of the three types of marital goals is under dynamic changes across adulthood. The theorists believe that young couples emphasize the personal growth goals, middle-aged couples prioritize the instrumental goals, and old couples focus on the companionship goals. Whether the prioritized marital goals are achieved in marriage or not determines Marital Satisfaction. Tramilton [30] on the other hand, believes that marriage is a complex and complicated situation and that if done right, can lead to a rewarding lifetime of fulfilment, companionship and joy. He argues that there are six components that bring about Marital Satisfaction, one of which is affection. However, people with Alexithymia find it difficult to identify affection provided by their partners which prevents them from experiencing satisfaction and they also find it difficult to express affection to their partners which their partners from experiencing satisfaction in their relationship and thus not communicating affect can be a stumbling block for Marital Satisfaction.

McNeill [31] investigated Alexithymia in 170 community couples in association with their empathy provided, empathy received, emotional connection components (i.e., turn toward, turn away, turn against, positive emotional connection), and relationship dissatisfaction. Toronto Alexithymia Scale (TAS-20), Barrett-Lennard Relationship Inventory, and revised Marital Satisfaction Inventory were used. Findings indicated that husbands' and wives' own TAS-20 scores predicted all of their own outcome variables in the expected positive and negative directions. Relationally, husbands' and wives' TAS-20 scores predicted higher partner relationship dissatisfaction.

Yelsma and Marrow [32] investigated a sample of 66 married couples to examine the impact of difficulties with emotional expressiveness on Marital Satisfaction. The Toronto Alexithymia Scale and the Dyadic Adjustment Scale was used. Results from 2 piece-wise regression models indicated that both husbands' and wives' difficulties with emotional expressiveness impaired their own, as well as their spouses' Marital Satisfaction. These findings suggest when either husbands or wives have lower levels of emotional expressiveness than their partners, their Marital Satisfaction will be negatively influenced, irrespective of the gender.

A possible reason for the obtained finding could be cultural influence and socialization. In Indian culture, females are expected to be more expressive than males. Moreover, this very expectation is inculcated into the socialization process with such intensity that it becomes difficult for the individual to go against the societal norms. Hence, this could be a possible base to higher Alexithymia in males than in females. Moreover, this implied expectation, harsher for males, tends to create a personal conflict within them regarding the decision to express or not to express emotions, thus leading them to experience Neuroticism, and hence the finding that men with high Neuroticism tend to be more Alexithymic than women. Thus, gender seems to have a major influence on one's Neuroticism and Alexithymia, which are both found to have an influence on Marital Satisfaction. Moreover, several other factors could influence this relationship like age, type of family, interaction and communication patterns, socioeconomic status, etc. These factors 
could be studied in different combinations to see the ways in which they could influence the interrelationship between these variables.

Moreover, future research which would be conducted would be able to provide implications for how the relationship is shaped by cultural factors and the major underlying factors could in turn be utilized to tackle the problems arising out of the imbalance of these variables and its toll on Marital Satisfaction and lastly, it could be used in helping the couples increase their relationship satisfaction. Lastly, this thesis will add to the understanding of the impact of Neuroticism on Alexithymia and Marital Satisfaction and the relationship between these two dependent variables among married men and women. However, there a few limitations to the current study and these should be taken into consideration.

\section{Limitations}

Neuroticism is a very important component of the big five personality constructs and studies have shown the impact of one variable on other big five constructs. However, in the current study, only Neuroticism was focused upon as an important variable impacting Alexithymia and Marital Satisfaction. Thus, further work can be done by taking into consideration the impact of other big five constructs on the dependent variables. In addition, even if it is assumed that the participants would have responded honestly to the test items, it is more likely that the responses would not be as honest on the scale of Marital Satisfaction. This can be seen from the participants scores on Idealistic Distortion sub scale of ENRICH Marital Satisfaction Scale. The responses were distorted so as to present the Marital Satisfaction in a very positive light and hence the significance of the results pertaining to this remains a question. Moreover, Marital Satisfaction includes several components like intimacy, sexual satisfaction, compatibility, adjustment and so on. However, these components were not studied separately in the present study. Lastly, the construct of Alexithymia has three major components- difficulty in describing feelings, difficulty in identifying feelings and externally oriented thinking. These components were not taken separately and instead were studied as a whole. This could have limited the scope of the present study. Despite the above-mentioned limitations, the present study still provides implications and applications for the obtained findings.

\section{REFERENCES}

1. Markman HJ. Application of a behavioral model of marriage in predicting relationship satisfaction of couples planning marriage. J Consult Clin Psychol 1979;47(4):743-55.

2. McHale SM, Huston TL. The effect of the transition to parenthood on the marriage relationship: A longitudinal study. J Fam Issues 1985;6(4):409-33.

3. Lewis RA, Spanier GB. Marital quality, marital stability, and social exchange. Family relationships: Rewards and costs. Beverly Hills; 1982.

4. Weiss RL. Contracts, cognition, and change: A behavioral approach to marriage therapy. The Counsel Psychol 1975;5(3):15-26.

5. Wills TA, Weiss RL, Patterson GR. A behavioral analysis of the determinants of marital satisfaction. J Consult Clin Psychol 1974;42(6):802-8.

6. Fincham FD, Bradbury TN. Cognition in marriage: A program of research on attributions. American Psychiatric Publishing ; 1991.

7. Gottman JM. The mathematics of marriage: Dynamic nonlinear models. MIT Press; 2005.

8. Holmes J. John Bowlby and attachment theory. Routledge; 2014.

9. Gottman JM. The marriage clinic: A scientifically-based marital therapy. WW Norton \& Company; 1999.

10. Gottman JM, DeClaire J, Gottman J. The relationship cure. New York: Three Rivers Press; 2001.

11. Olsen DC, Stephens DB. The Couple's Survival Workbook: What You Can Do to Reconnect with Your Partner and Make Your Marriage Work. Oakland, CA: New Harbinger Publications; 2001.

12. Stevens G, Owens D, Schaefer EC. Education and attractiveness in marriage choices. Soc Psychol Quart 1990; $1: 62-70$.

13. Karney BR, Bradbury TN. Assessing longitudinal change in marriage: An introduction to the analysis of growth curves. J Marr Family 1995;3:1091-108.

14. Kelly GA. Personal construct theory and the psychotherapeutic interview. Cogn Ther Res 1977;1(4):355-62.

15. Côté S, Moskowitz DS. On the dynamic covariation between interpersonal behavior and affect: prediction from neuroticism, extraversion, and agreeableness. J Personal Soc Psychol 1998;75(4):1032-8. 
16. Barrett PT, Petrides KV, Eysenck SB, Eysenck HJ. The Eysenck Personality Questionnaire: An examination of the factorial similarity of P, E, N, and L across 34 countries. Personal Individ Diff 1998;25(5):805-19.

17. Leising D, Grande T, Faber R. The Toronto Alexithymia Scale (TAS-20): A measure of general psychological distress. J Res Personality 2009;43(4):707-10.

18. Parker JD, Michael Bagby R, Taylor GJ, Endler NS, Schmitz P. Factorial validity of the 20- item Toronto Alexithymia Scale. Eur J Personality 1993;7(4):221-32.

19. Parker JD, Taylor GJ, Bagby RM. The 20-Item Toronto Alexithymia Scale: III. Reliability and factorial validity in a community population. J Psychosom Res 2003;55(3):269-75.

20. Schumm WR, Bollman SR, Jurich AP. Validity of Edmond's Marital Conventionalization Scale. J Psychology 1981;109(1):65-71.

21. Fowers BJ, Olson DH. ENRICH Marital Satisfaction Scale: A brief research and clinical tool. J Fam Psychol 1993;7(2):176-81.

22. Mamun AA, Clavarino AM, Najman JM, Williams GM, O'Callaghan MJ, Bor W. Maternal depression and the quality of marital relationship: a 14-year prospective study. J Wom Health 2009;18(12):2023-31.

23. Bradbury TN, Fincham FD, Beach SR. Research on the nature and determinants of marital satisfaction: A decade in review. J Marr Family 2000;62(4):964-80.

24. Goodwin R, Cramer D. Marriage and social support in a British-Asian community. J Commun Appl Soc Psychol 2000;10(1):49-62.

25. Malouff JM, Thorsteinsson EB, Schutte NS, Bhullar N, Rooke SE. The five-factor model of personality and relationship satisfaction of intimate partners: A meta-analysis. J Res Personality 2010;44(1):124-7.

26. Caughlin JP, Huston TL, Houts RM. How does personality matter in marriage? An examination of trait anxiety, interpersonal negativity, and marital satisfaction. J Personal Soc Psychol 2000;78(2):326-30.

27. McNulty JK. Forgiveness increases the likelihood of subsequent partner transgressions in marriage. J Fam Psychol 2010;24(6):787-95.

28. Segrin C, Hanzal A, Domschke TJ. Accuracy and bias in newlywed couples' perceptions of conflict styles and the association with marital satisfaction. Commun Monographs 2009;76(2):207-33.

29. Li T, Fung HH. The dynamic goal theory of marital satisfaction. Rev Gen Psychol 2011;15(3):246-54.

30. Barry WA. Marriage research and conflict: An integrative review. Psychol Bull 1970;73(1):41-9.

31. McNeil SN, Fincham FD, Beach SR. Does spousal support moderate the association between perceived racial discrimination and depressive symptoms among African American couples?. Fam Process 2014;53(1):109-19.

32. Yelsma P, Marrow S. An examination of couples' difficulties with emotional expressiveness and their marital satisfaction. J Fam Commun 2003;3(1):41-62.

$* * * * * * * * * * * * * * * * * * * * * * * * * * * * * * * * * * * *$

$$
\begin{gathered}
\text { Acknowledgements - Nil } \\
\text { Conflict of Interest - Nil } \\
\text { Funding - Nil }
\end{gathered}
$$

